\title{
Tuning surface chemistry and ionic strength to control nanoparticle adsorption and elastic dilational modulus at the air-brine interface
}

Chang $\mathrm{Da}^{11}$, Xuan Zhang ${ }^{11,2}$, Shehab Alzobaidi' ${ }^{1}$, Dongdong $\mathrm{Hu}^{1,3}$, Pingkeng

$\mathrm{Wu}^{* 1}$ and Keith P. Johnston*1

1 McKetta Department of Chemical Engineering and Texas Materials Institute, The University of Texas, Austin, TX, USA

2. College of Petroleum Engineering, China University of Petroleum, Qingdao, China

3. State Key Laboratory of Chemical Engineering, East China University of Science and Technology, Shanghai, China

${ }^{\ddagger}$ Equal contribution

* Corresponding Authors

Email: wupingjianwhu@gmail.com

Email: kpj@che.utexas.edu

\section{Contents}

S1. Dynamic surface tension and $E^{\prime}$ measurements at steady state

Fig. S1 A). Dynamic surface tension $(\gamma)$ and the dilational modulus $\left(E^{\prime}\right)$ versus time for $1 \% 1.5$-DM $\mathrm{NP}$ in $15 \%$ TDS brine. The $E$ ' was measured with a sinusoidal change in droplet area at $0.1 \mathrm{~Hz}$; B). Linear fit of IFT versus time with $1 \mathrm{wt} \%$ 1.5-DM NPs in $10 \% \mathrm{NaCl}$ to derive the adsorption energy predicted by the Ward \& Tordai equation (see below) in the first $225 \mathrm{~s}$.

Fig. S2 A). Effect of NP concentration on the elastic component of dilational modulus ( $\left.E^{\prime}\right)$ of 1.5-DM NPs in 15\% TDS brine; B). Dilational modulus versus frequency for ED-NPs and 1.5-DM NPs; C). viscous dilational modulus measured at the NP-laden water-air interface with $1 \mathrm{wt} \%$ NPs with various DM coverages in $15 \%$ TDS brine, as the supplement to Figure 2A in main text; D). viscous dilational modulus measured at the NP-laden water-air interface with $1 \mathrm{wt} \% 1.5$-DM NPs for various salinities,

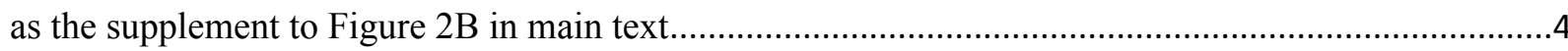

S2. Needle size analysis and Worthington (Wo) number of pendant drops …..................................

Table S1. Wo numbers for both 2-mm and 4-mm needles as a function of surface area for 15\% TDS brine.

S3. Contact angle for NPs at brine-air or water-air interface .6

Table S2. Contact angles of NPs at air-water or air-brine interface with surface-modified silica NPs ....6

S4. Correlation between surface pressure $\Pi$ and surface area A for electrostatic dipolar repulsion .7

Fig. S3 Surface pressure (П) plotted verses surface area for 1\% 1.5-DM NPs in dispersions with various salinities during $3^{\text {rd }}$ compression. The surface pressure was normalized with an exponential of 2 following the procedure of Karnieli $2018^{13}$ 
Fig. S4. П-A isotherm curves of 1\% 1.5-DM in A). $15 \%$ TDS, B). $10 \% \mathrm{NaCl}$ and C). DI water during the $3^{\text {rd }}$ compression and expansion cycle. The dashed line shows the 3 rd-order polynomial fitting to the $\Pi$-A curves used to calculate $\mathrm{E}_{0}$ shown in Figure 5. 8

Fig. S5 П-A isotherms of $1 \mathrm{wt} \%$ 1.5-DM NPs in DI water during first 3 compression-expansion cycles same as Figure 5(III)(b), with each panel showing only one cycle; in each panel compression was shown with the colored dots, while expansion was shown in black dots. In DI water there was little aggregation as is evident in slight hysteresis.

S6. Comparison of compression rates for sinusoidal and continuous compression .9

Table S3. Compression rate $\left(\mathrm{s}^{-1}\right)$ calculated based on definition in Zang $2010^{1}$ for our work and various studies.

\section{S1. Dynamic surface tension and $E^{\prime}$ measurements at steady state}

A).

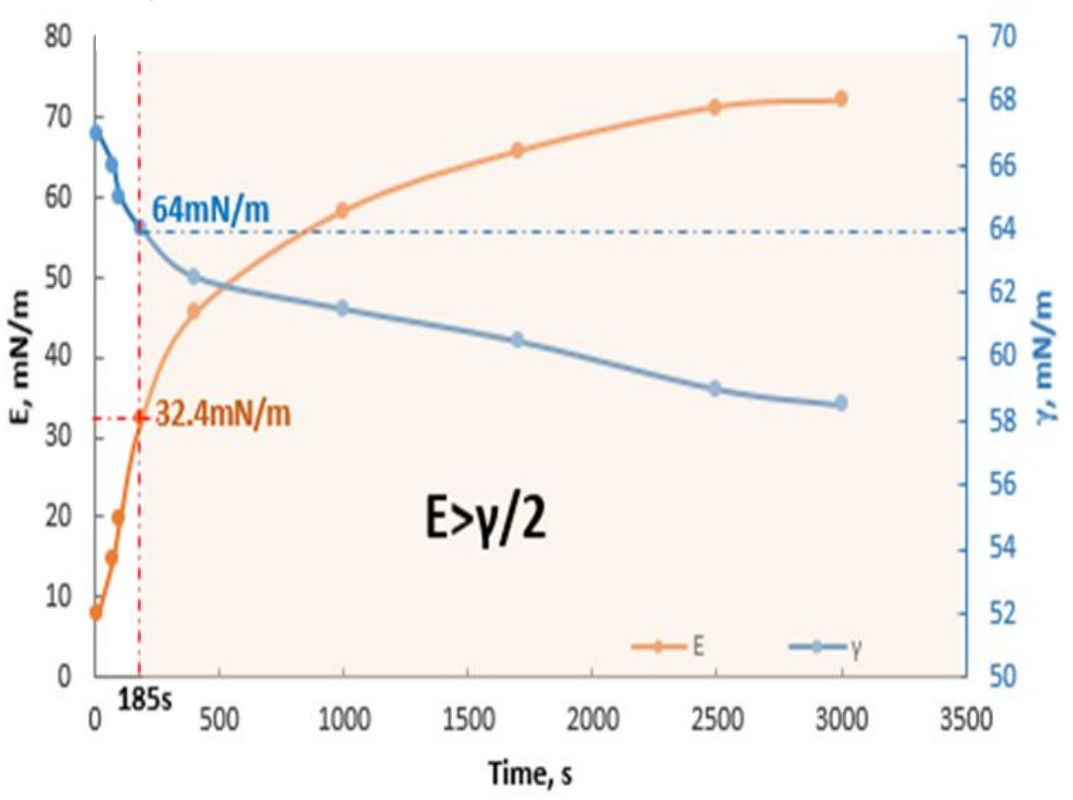

B).

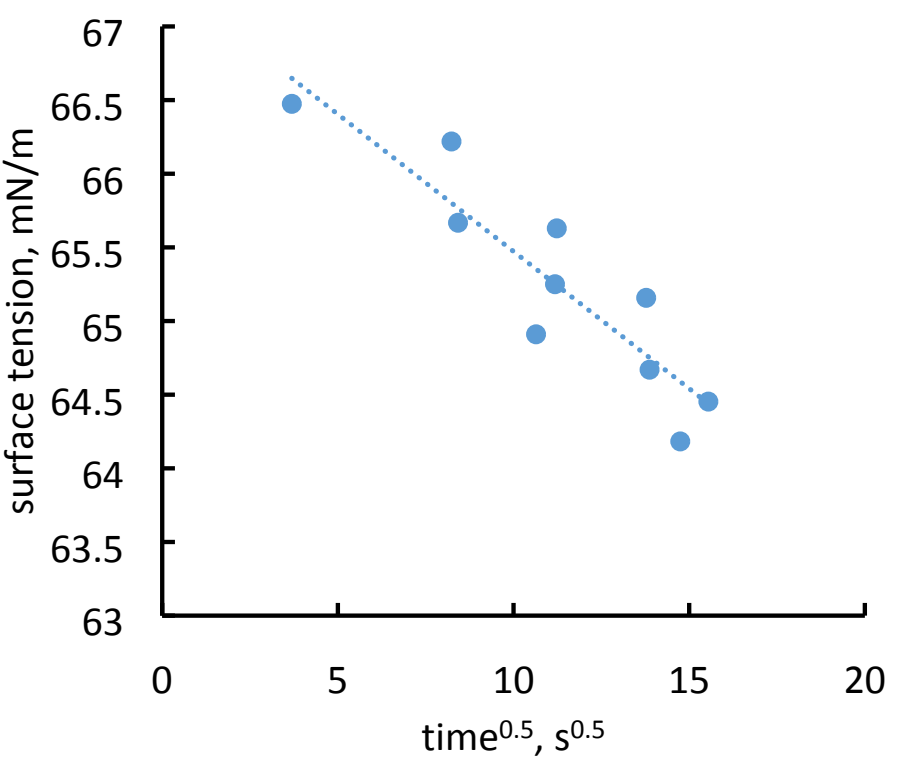

Fig. S1 A). Dynamic surface tension $(\gamma)$ and the dilational modulus $\left(E^{\prime}\right)$ versus time for $1 \% 1.5$-DM NP in $15 \%$ TDS brine. The $E$ ' was measured with a sinusoidal change in droplet area at $0.1 \mathrm{~Hz}$; B). Linear fit of IFT versus $\sqrt{\text { time }}$ with $1 \mathrm{wt} \%$ 1.5-DM NPs in $10 \% \mathrm{NaCl}$ to derive the adsorption energy predicted by the Ward \& Tordai equation (see below) in the first $225 \mathrm{~s}$. 
The Gibbs criteria shown in Fig S1 A) was defined for the condition where a single bubble/droplet would be stable without continuous dissolution due to the change in Laplace pressure $\left(\left(\Delta P=P_{\text {in }}-P_{\text {ext }}=2 \gamma / R\right)^{1}\right.$. Without presence of compression elasticity, the change in bubble pressure due to change in bubble radius is always negative: $\frac{d \Delta P}{d R}=\frac{-2 \gamma}{R^{2}}$, which leads to an unstable situation and increased dissolution of the bubble. However, with the presence of a compression modulus $E$, the situation could be positive as $\frac{d \Delta P}{d R}=\frac{-2 \gamma}{R^{2}}+\frac{4 E}{R^{2}}>0$ if we have $E>\gamma / 2$. Then the bubble pressure decreases as its radius decreases, and the bubble dissolution slows down until it is stable against dissolution when $\Delta P=0^{1}$. Thus we consider the coarsening of the foams to stop when the Gibbs criteria is satisfied, and the foams to be much more stable ${ }^{1}$.

Martinez et.al ${ }^{2}$ pointed out that in the case of surfactants, the condition of $E>\gamma / 2$ is usually satisfied but the foams could still coarsen. This is due to the fact that upon slow compression on the interface, surfactant can desorb and thus the surface coverage is no longer inversely proportional to A. Thus, the apparent resistance to compression become smaller than the theoretical value shown as $E=-A d \Pi / d A$, which applies only to fast compressions or insoluble monolayers. Unlike the case with surfactants, the resistance provided from E with NPs irreversibly adsorbed at the interface is thus more capable of preventing coarsening.

Other factors were reported in literature that could be contributed to the resistance on the compression, in addition to the interfacial elasticity. For example, Beltramo er.al claimed that the yield stress is also a key component to the resistance, and when $\Delta \mathrm{P}$ overcomes the opposing forces of IFT, elasticity, and yield, the bubble will shrink ${ }^{3}$.

The linear fit in Fig S1 B) was applied to the Ward \& Tordai equation ${ }^{4}, \gamma=\gamma_{0}-2\left|\Delta E_{a d}\right| C_{0}$ $\sqrt{\frac{D t}{\pi}}$, in which $\Delta E_{a d}$ denotes the adsorption energy at the interface, $C_{0}$ denotes the initial NP concentration in bulk phase, $\mathrm{D}$ denotes the diffusion coefficient which was estimated from the Stokes-Einstein equation $\left(D=\frac{k_{B} T}{6 \pi \eta r}\right.$, in which $\mathrm{k}_{\mathrm{B}}$ is the Boltzmann's constant, $\mathrm{T}$ is the absolute temperature, $\eta$ is the dynamic viscosity, and $\mathrm{r}$ is the radius of the particle, $20 \mathrm{~nm}$ ). The estimated $\Delta E_{a d}$ based on Ward \& Tordai equation and Fig S1 B) was $\sim 4.06^{*} 10^{3} \mathrm{kT}$, which approximated the values calculated from $\Delta E=-\pi r^{2} \gamma_{0}(1-|\cos \theta|)^{2}$ shown in Table 2 . Note that $\mathrm{D}$ is also dependent on the brine salinity as it modifies the viscosity. 

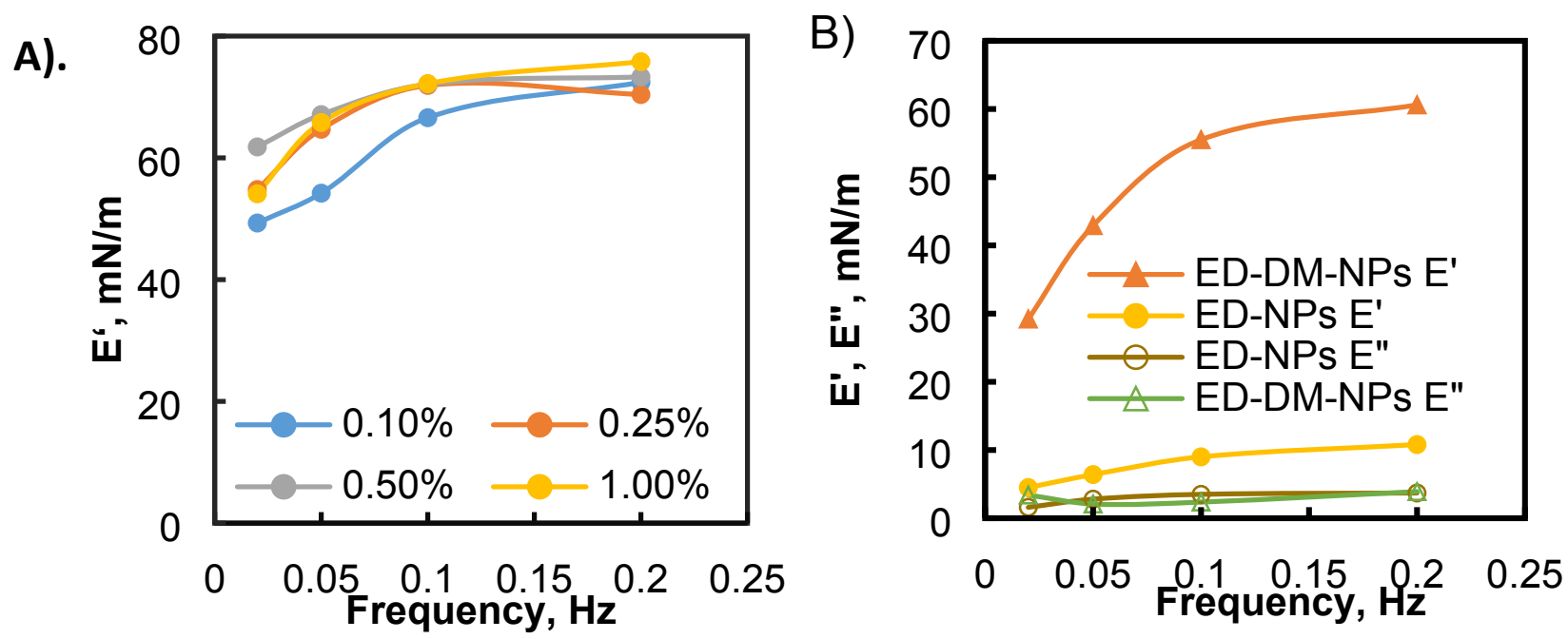

C).

D)
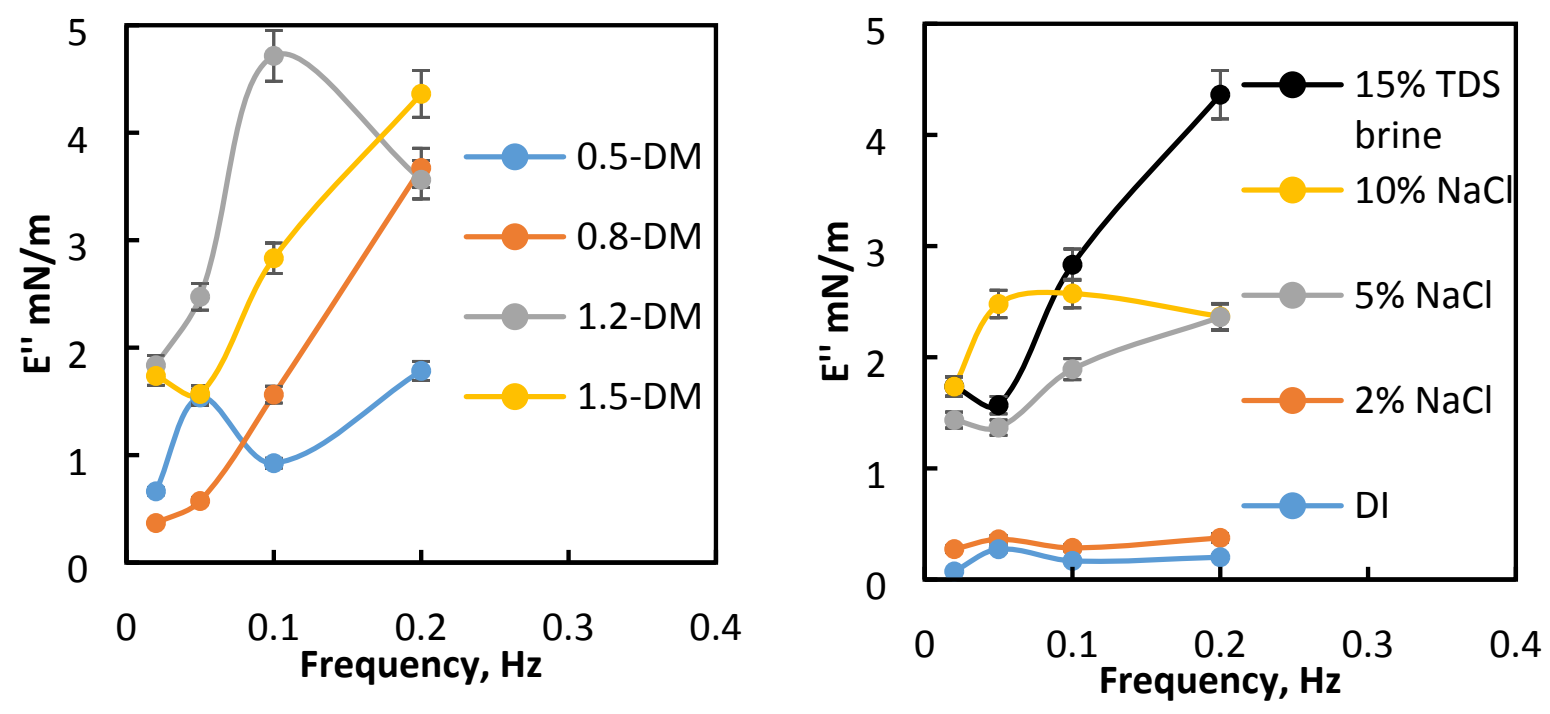

Fig. S2 A). Effect of NP concentration on the elastic component of dilational modulus ( $\left.E^{\prime}\right)$ of 1.5-DM NPs in 15\% TDS brine; B). Dilational modulus versus frequency for ED-NPs and 1.5-DM NPs; C). viscous dilational modulus measured at the NP-laden water-air interface with $1 \mathrm{wt} \%$ NPs with various DM coverages in $15 \%$ TDS brine, as the supplement to Figure 2A in main text; D). viscous dilational modulus measured at the NP-laden water-air interface with $1 \mathrm{wt} \% 1.5$-DM NPs for various salinities, as the supplement to Figure 2B in main text 


\section{S2. Needle size analysis and Worthington (Wo) number of pendant drops}

Table S1. Wo numbers for both 2-mm and 4-mm needles as a function of surface area for $15 \%$ TDS brine

\begin{tabular}{|l|l|l|l|l|l|l|}
\hline \multirow{2}{*}{$\begin{array}{l}\text { Needle size and NP } \\
\text { Hydrophobicit }\end{array}$} & \multicolumn{5}{|c|}{ Surface area during compression } \\
\cline { 2 - 7 } & $50\left(\mathrm{~mm}^{2}\right)$ & $40\left(\mathrm{~mm}^{2}\right)$ & $30\left(\mathrm{~mm}^{2}\right)$ & $23\left(\mathrm{~mm}^{2}\right)$ & $16\left(\mathrm{~mm}^{2}\right)$ \\
\cline { 2 - 7 } & $0.5 \mathrm{Dm}$ & & 0.63 & 0.47 & 0.33 & \\
\cline { 2 - 7 } & $0.8 \mathrm{DM}$ & & 0.65 & 0.49 & 0.36 & \\
\cline { 2 - 7 } & $1.2 \mathrm{DM}$ & & 0.69 & 0.57 & 0.4 & \\
\cline { 2 - 7 } & $1.5 \mathrm{DM}$ & & 0.65 & 0.55 & 0.39 & 0.18 \\
\hline $4 \mathrm{~mm}$ & $1.5 \mathrm{DM}$ & 0.53 & 0.5 & 0.48 & $\mathbf{0 . 4 5}$ & $\mathbf{0 . 2 5}$ \\
\hline
\end{tabular}

The Worthington (Wo) number was proposed by Berry et.al ${ }^{5}$ as a non-dimensional number that scales the drop volume $V_{d}$ by the theoretical maximum drop volume $V_{\text {max }}: W o=$ $V_{d} / V_{\max }$. This non-dimensional quantity scales from 0 to 1 to account for the volume effect on interfacial tension (IFT) measurements. Accurate and precise surface tension measurements can be obtained when the Wo number is large ${ }^{5}$. Compared to the Bond (Bo) number, the Wo number was shown to be more successful for indicating accuracy in the interfacial tension ${ }^{5}$. Upon applying the theoretical maximum drop volume $\left(V_{\max }=\frac{\pi D_{n} \gamma}{\Delta \rho g}\right)$ defined by Harkins and Brown ${ }^{6-7}$, the equation for calculating Wo number can be rewrite as $W o=\frac{\Delta \rho g V_{d}}{\pi \gamma D_{n}}$, in which $D n$ is the needle diameter $^{5}$. In Table S1, the Wo number is larger for the 4-mm diameter needle than the 2-mm needle for surface areas of 23 and $16 \mathrm{~mm}^{2}$. Thus, the 2-mm needle was used only for steady state experiments. All experiments with compression or expansion used a 4-mm needle for the $\Pi-A$ isotherm and $E_{o}$ and $E^{\prime}$ studies. 


\section{S3. Contact angle for NPs at brine-air or water-air interface}

Table S2. Contact angles of NPs at air-water or air-brine interface with surface-modified silica NPs

\begin{tabular}{|c|c|c|c|}
\hline & NPs & $\begin{array}{l}\text { Contact angle between } \\
15 \% \text { TDS brine and air, }\end{array}$ & $\begin{array}{c}\text { Contact angle between DI } \\
\text { water and air, }{ }^{\circ}\end{array}$ \\
\hline \multirow[t]{4}{*}{$\begin{array}{l}\text { ED-DM in } \\
\text { this study }\end{array}$} & $0.5-\mathrm{DM}$ & $47 \pm 4$ & \\
\hline & 0.8-DM & $57 \pm 2$ & \\
\hline & 1.2-DM & $64 \pm 4$ & \\
\hline & $1.5-\mathrm{DM}$ & $75 \pm 3$ & $52 \pm 3$ \\
\hline \multirow{4}{*}{$\begin{array}{c}\text { Razavi } \\
\text { Kretzchmar } \\
2015\end{array}$} & S1 (most hydrophobic) & & $97 \pm 2$ \\
\hline & S2 & & $84 \pm 3$ \\
\hline & S3 & & $70 \pm 4$ \\
\hline & S4 (most hydrophilic) & & $57 \pm 3$ \\
\hline \multirow[t]{5}{*}{$\begin{array}{c}\text { Safouane } \\
\text { Binks } 2007\end{array}$} & $\begin{array}{c}100 \% \mathrm{SiOH} \text { (most } \\
\text { hydrophilic) }\end{array}$ & & $20 \pm 5$ \\
\hline & $71 \% \mathrm{SiOH}$ & & $40 \pm 5$ \\
\hline & $51 \% \mathrm{SiOH}$ & & $100 \pm 10$ \\
\hline & $36 \% \mathrm{SiOH}$ & & $120 \pm 10$ \\
\hline & $\begin{array}{l}20 \% \mathrm{SiOH} \text { (most } \\
\text { hydrophobic) }\end{array}$ & & $135 \pm 10$ \\
\hline
\end{tabular}




\section{S4. Correlation between surface pressure $\Pi$ and surface area $A$ for electrostatic dipolar repulsion \\ - In $15 \%$ TDS brine $\quad$ In $10 \% \mathrm{NaCl}$ In DI water}

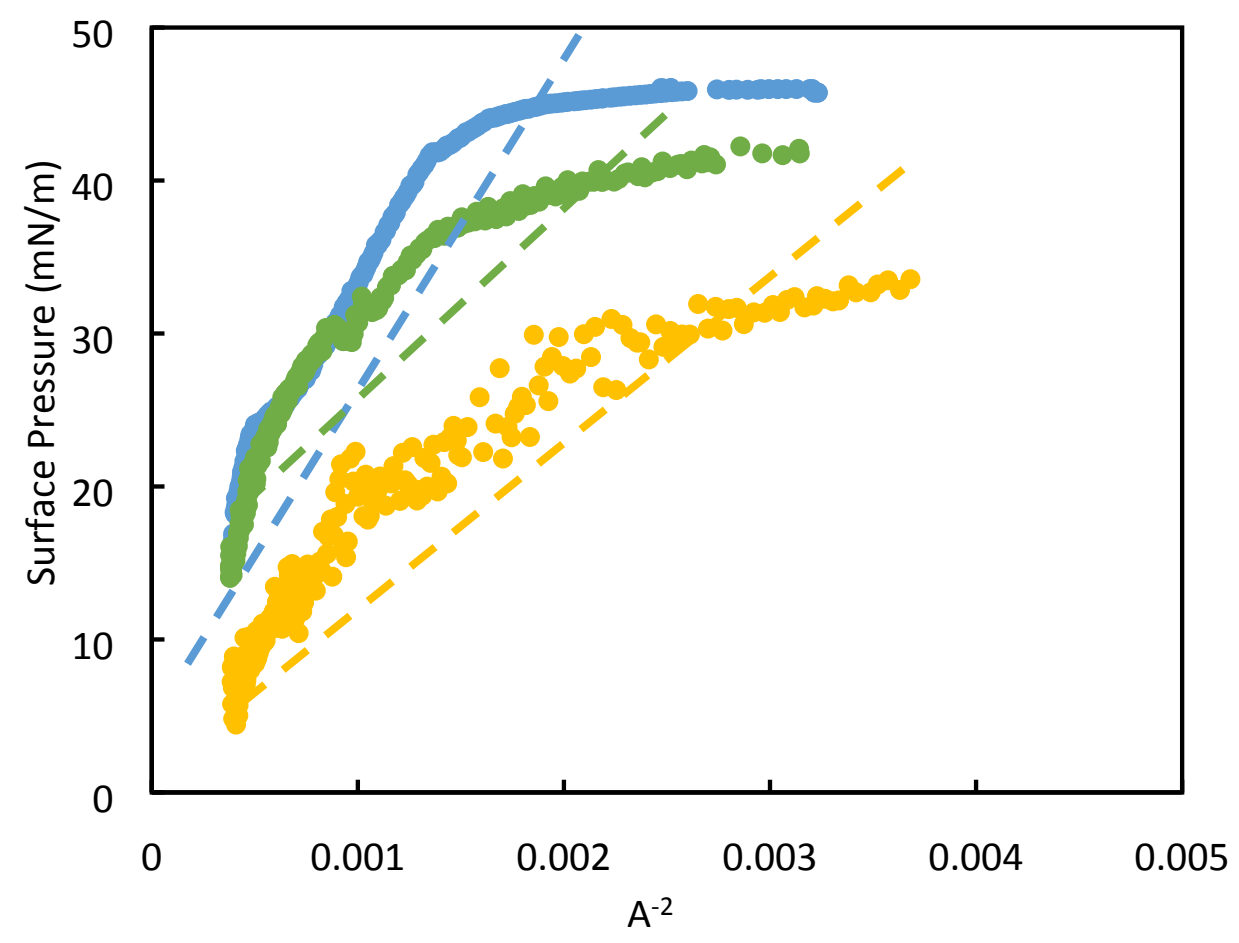

Fig. S3 Surface pressure (П) plotted verses surface area for 1\% 1.5-DM NPs in dispersions with various salinities during $3^{\text {rd }}$ compression. The surface pressure was normalized with an exponential of -2 following the procedure of Karnieli $2018^{13}$

Fig S3 is described in section 3.4 in the main text. Furthermore, the slope of the curves increased with brine salinity, which can be explained by the larger aggregates formed at the interface with increased electrolyte concentration ${ }^{8}$. Thus the model could described key aspects of the electrostatic interactions between NPs in the monolayer at the interface ${ }^{8-9}$. 


\section{S5. Surface pressure during compression and expansion}
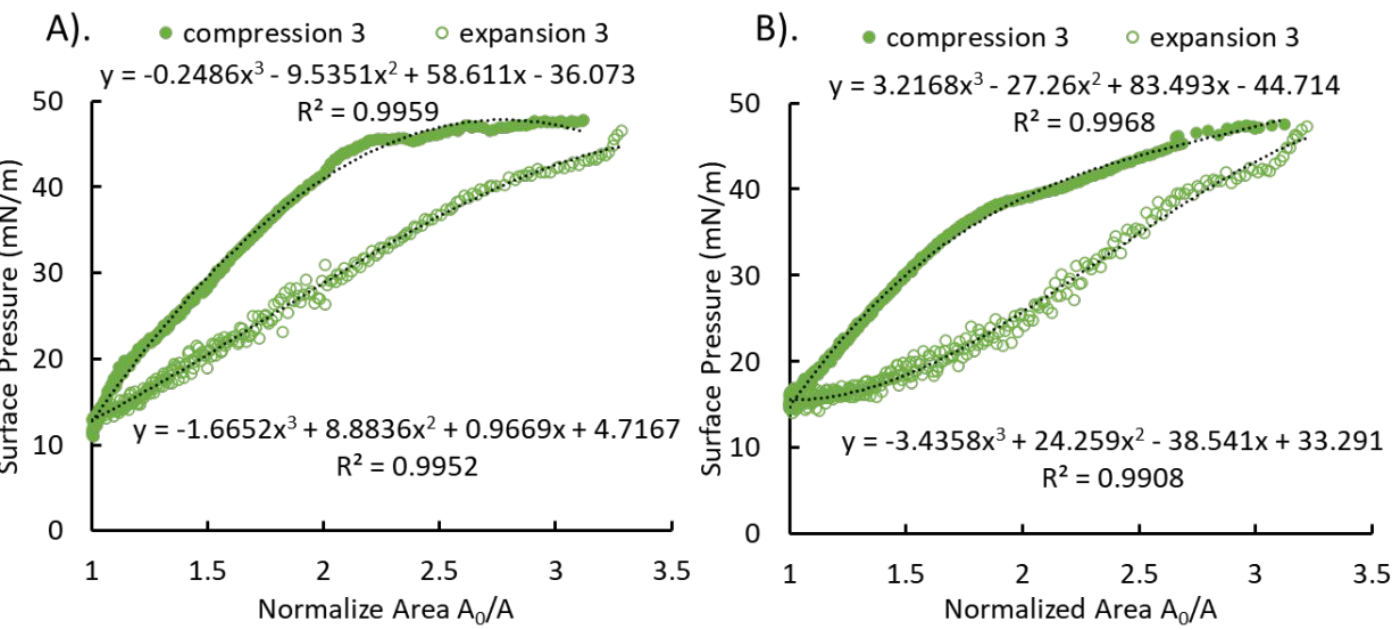

C). compression 3 expansion 3

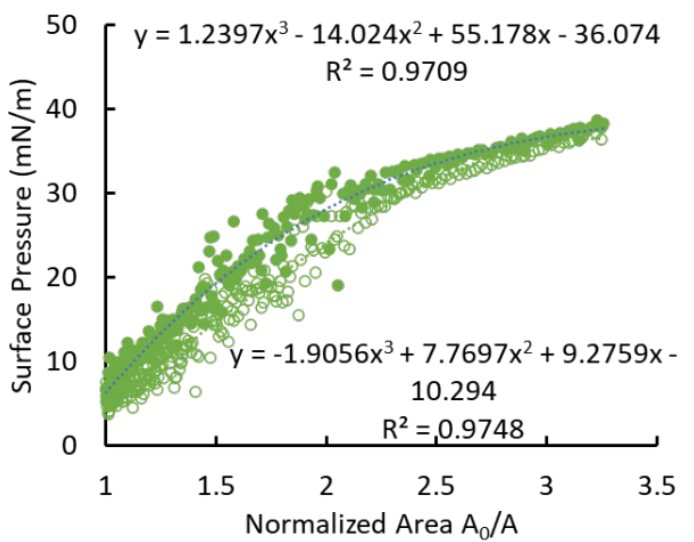

Fig. S4. П-A isotherm curves of 1\% 1.5-DM in A). 15\% TDS, B). $10 \% \mathrm{NaCl}$ and C). DI water during the $3^{\text {rd }}$ compression and expansion cycle. The dashed line shows the 3 rd-order polynomial fitting to the $\Pi-A$ curves used to calculate $\mathrm{E}_{\mathrm{o}}$ shown in Figure 5.

\section{$1^{\text {st }}$ cycle}

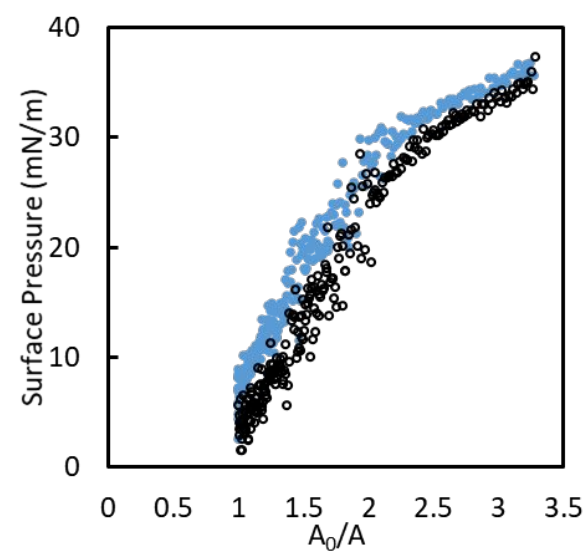

$2^{\text {nd }}$ cycle

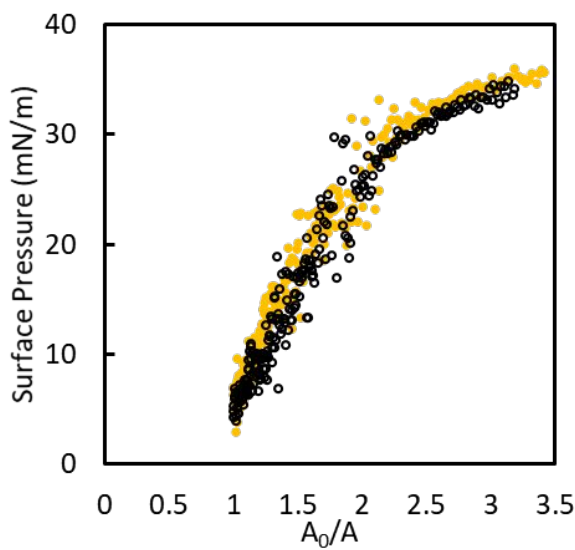

$3^{\text {rd }}$ cycle

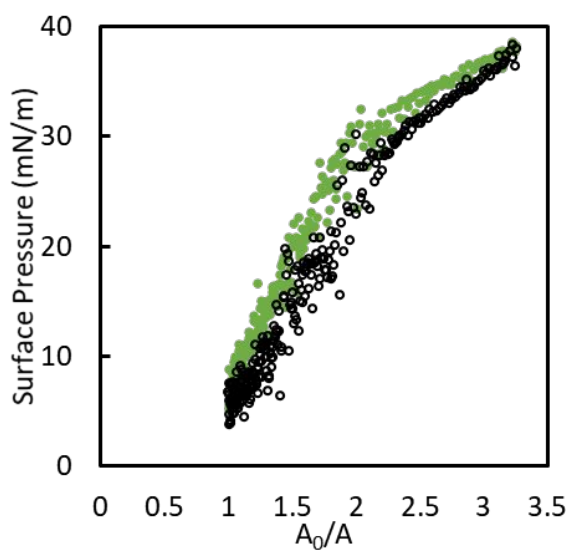

Fig. S5 П-A isotherms of $1 \mathrm{wt} \%$ 1.5-DM NPs in DI water during first 3 compression-expansion cycles same as Figure 5(III)(b), with each panel showing only one cycle; in each panel compression was shown with the colored dots, while expansion was shown in black dots. In DI water there was little aggregation as is evident in slight hysteresis. 


\section{S6. Comparison of compression rates for sinusoidal and continuous compression}

Table S3. Compression rate $\left(\mathrm{s}^{-1}\right)$ calculated based on definition in Zang $2010^{1}$ for our work and various studies

\begin{tabular}{|c|c|c|c|}
\hline & Sinusoidal oscillation & $\begin{array}{l}\text { Continuous } \\
\text { compression }\end{array}$ & Comments \\
\hline \multirow[t]{2}{*}{ Our experiments } & \multirow[t]{2}{*}{$0.01-0.04$} & $\begin{array}{l}0.0025-0.0075 \\
\text { with } 2 \mathrm{~mm} \text { tube }\end{array}$ & $\begin{array}{l}\text { Droplet surface area } 40 \\
-15 \mathrm{~mm}^{2} ; \mathrm{f}=0.1 \mathrm{~Hz}\end{array}$ \\
\hline & & $\begin{array}{l}0.0015-0.0067 \\
\text { with } 4 \mathrm{~mm} \text { conical tube }\end{array}$ & $\begin{array}{l}\text { Droplet surface area } 50 \\
-18 \mathrm{~mm}^{2} ; \mathrm{f}=0.1 \mathrm{~Hz}\end{array}$ \\
\hline Zang 2010 Binks $^{10}$ & $\begin{array}{l}0.0003-0.01 \\
0.002-0.06\end{array}$ & $\begin{array}{l}0.0001-0.001 \\
0.001-0.01 \\
\end{array}$ & $\begin{array}{l}\text { Table } 2 \\
\mathrm{~A}_{\text {init. }}=500 \mathrm{~cm}^{2}\end{array}$ \\
\hline Safouane 2007 Binks $^{11}$ & 10 & 0.004 & $\begin{array}{l}\mathrm{f}=200-1000 \mathrm{~Hz} \\
\mathrm{~A}_{\text {init. }}=724 \mathrm{~cm}^{2} \text { for } \\
\text { oscillation and } 100 \mathrm{~cm}^{2} \\
\text { for static compression }\end{array}$ \\
\hline Liggieri $2011^{12}$ & $\begin{array}{l}\text { Amplitude not } \\
\text { specified } \\
\text { Frequency shown as } \\
0.1-10 \mathrm{~Hz} \\
10-1200 \mathrm{~Hz}\end{array}$ & 0.0001 & $\begin{array}{l}A_{\text {init }}=243 \mathrm{~cm}^{2} \\
\text { Compression rate } \\
2 \mathrm{~cm}^{2} / \mathrm{min}\end{array}$ \\
\hline Kirby 2018 Walker $^{13}$ & $\begin{array}{l}\text { Amplitude not } \\
\text { specified } \\
\text { Frequency shown as } \\
1.9 \mathrm{rad} / \mathrm{s}\end{array}$ & 0.002 & $\begin{array}{l}\text { Cap radius } r=35 \mu \mathrm{m} \\
\text { Compression rate on } \\
\text { average } 1000 \mu \mathrm{m}^{2} / \mathrm{min}\end{array}$ \\
\hline
\end{tabular}

The compression rate was defined as $\left(\frac{d A}{d t}\right) / A$ in the unit of $\mathrm{s}^{-1}$, as mentioned in Zang et.al ${ }^{10}$. In their study, they claimed that the compression rate could significantly influence the relaxation of the NP adsorption layer at the interface ${ }^{10}$. For example, when the barrier speed on the Langmuir trough during compression was reduced from 25 to $7 \mathrm{~cm}^{2} / \mathrm{min}$ (Table S3), the compression rate was reduced by almost one orders magnitude (from $0.002-0.06 \mathrm{~s}^{-1}$ to $0.0003-$ $0.01 \mathrm{~s}^{-1}$ ), and the dilational modulus $E$ measured with Langmuir trough became significantly lower (shown in Figure 12 of Zang et.al) ${ }^{10}$. In our experiments, the compression rate for sinusoidal oscillation (0.01-0.04 s $\mathrm{s}^{-1}$ with a period of $\sim 10 \mathrm{~s}$ or frequency of $0.1 \mathrm{~Hz}$ ) was almost one order of magnitude higher than that during continuous or static compression $(0.0015-$ $0.0067 \mathrm{~s}^{-1}$ with a constant volumetric rate of $0.1 \mu \mathrm{L} / \mathrm{s}$ ). This difference may be used to explain lower values of Gibbs modulus $E_{o}$ measured from large-amplitude compression (Figure 5) compared to dilational modulus $E$ ' measured from sinusoidal oscillations (Figure 6). As the compression rate during static (continuous) compression is lower, the NPs at the interface has 
longer time to relax and rearrange during droplet compression compared to the case experiencing faster sinusoidal oscillation ${ }^{10}$. Thus the measured $E_{o}$ is generally lower than $E^{\prime}$ at the same conditions, as shown in multiple examples in literature ${ }^{2,3}$.

\section{References}

(1) Maestro, A.; Rio, E.; Drenckhan, W.; Langevin, D.; Salonen, A. Foams stabilised by mixtures of nanoparticles and oppositely charged surfactants: relationship between bubble shrinkage and foam coarsening. Soft matter 2014, 10 (36), 6975-6983.

(2) Martinez, A. C.; Rio, E.; Delon, G.; Saint-Jalmes, A.; Langevin, D.; Binks, B. P. On the origin of the remarkable stability of aqueous foams stabilised by nanoparticles: link with microscopic surface properties. Soft Matter 2008, 4 (7), 1531-1535.

(3) Beltramo, P. J.; Gupta, M.; Alicke, A.; Liascukiene, I.; Gunes, D. Z.; Baroud, C. N.; Vermant, J. Arresting dissolution by interfacial rheology design. Proceedings of the National Academy of Sciences 2017, 114

(39), 10373-10378.

(4) Bizmark, N.; loannidis, M. A.; Henneke, D. E. Irreversible adsorption-driven assembly of nanoparticles at fluid interfaces revealed by a dynamic surface tension probe. Langmuir 2014, 30 (3), 710-717.

(5) Berry, J. D.; Neeson, M. J.; Dagastine, R. R.; Chan, D. Y.; Tabor, R. F. Measurement of surface and interfacial tension using pendant drop tensiometry. Journal of colloid and interface science 2015, 454, 226-237.

(6) Garandet, J. P.; Vinet, B.; Gros, P. Considerations on the pendant drop method: a new look at Tate's law and Harkins' correction factor. Journal of colloid and interface science 1994, 165 (2), 351-354.

(7) Harkins, W. D.; Brown, F. The determination of surface tension (free surface energy), and the weight of falling drops: The surface tension of water and benzene by the capillary height method. Journal of the American Chemical Society 1919, 41 (4), 499-524.

(8) Petkov, P. V.; Danov, K. D.; Kralchevsky, P. A. Monolayers of charged particles in a Langmuir trough: Could particle aggregation increase the surface pressure? Journal of colloid and interface science 2016, 462, 223-234.

(9) Bykov, A.; Noskov, B.; Loglio, G.; Lyadinskaya, V.; Miller, R. Dilational surface elasticity of spread monolayers of polystyrene microparticles. Soft Matter 2014, 10 (34), 6499-6505.

(10) Zang, D.; Rio, E.; Langevin, D.; Wei, B.; Binks, B. Viscoelastic properties of silica nanoparticle monolayers at the air-water interface. The European Physical Journal E 2010, 31 (2), 125-134.

(11) Safouane, M.; Langevin, D.; Binks, B. Effect of particle hydrophobicity on the properties of silica particle layers at the air- water interface. Langmuir 2007, 23 (23), 11546-11553.

(12) Liggieri, L.; Santini, E.; Guzman, E.; Maestro, A.; Ravera, F. Wide-frequency dilational rheology investigation of mixed silica nanoparticle-CTAB interfacial layers. Soft Matter 2011, 7 (17), 7699-7709.

(13) Kirby, S. M.; Anna, S. L.; Walker, L. M. Effect of surfactant tail length and ionic strength on the interfacial properties of nanoparticle-surfactant complexes. Soft matter 2018, 14 (1), 112-123. 